\title{
Changes of River's Water Quality Responded to Rainfall Events
}

\author{
Hun-Kyun Bae \\ Dept. of Global Environment, School of Environment, Keimyung University, Dalsequ, 704-701, Daegu, Korea \\ *Corresponding Author: hunkyunbae@kmu.ac.kr
}

Copyright (C) 2013 Horizon Research Publishing All rights reserved.

\begin{abstract}
The study focused on changes of river's water quality dependent on rainfall events. Hwang River, at South Korea was chosen for the study. Water samples at up and downstream of Hwang River were collected for three different rainfall events on Sep. $10^{\text {th }} 2011$, Jul. $14^{\text {th }} 2012$, and Aug. $13^{\text {th }}$ 2012. Samples were analyzed for COD, TSS, T-N and T-P. As results, the changes of water quality due to rainfall events were dependent on the amount of precipitations as well as patterns of rainfall event. Also, changes of water quality at upstream were affected by the amount of discharges from Hapcheon Dam located in upper side of the river. For proper management of Hwang River's water quality, plans for early rainfall events after long-term dry season should be established.
\end{abstract}

Keywords Water quality, Hwang River, Rainfall event

\section{Introduction}

Rivers are the major water resources in Korea. Water qualities of rivers tend to getting worse because of pollutants from surrounding watersheds [1,2]. In addition, changes of flow rate of rivers between rainy season and dry season could bring difficulties to maintain river's water quality $[3,4]$. River's water quality might be affected by various factors. Among them, non-point source pollutants are the main concern for river's water quality management and rainfall events play a very important role as carriers for non-point source pollutants moving to the waterbody [1]. For example, Whilock et al. [5] reported the strong relationship between rainfall events and fecal coliform concentrations at Tempa Bay. Also, Noble et al. [6] reported that the concentrations of indicator bacteria in the coastal zones along the Southern California during the storm event were 5 to 40 times higher than any other seasons in the same year. Therefore, stromwater managements could be the key issue to manage river's water quality.

In this study, effects of early rainfall events on river's water quality were investigated focused on Hwang River, one of main branches of the biggest river in Korea, Nakdong River. The river runs through mountain area, agricultural area as well as urbanized area, so that results of this study would give some ideas to the researchers who are interested in rainfall effects on river's water quality with various types of watershed.

\section{Materials and Methods}

\subsection{Study Area and Sampling Points}

Figure 1 shows the study area. Hwang River is the one of main branches of Nakdong River, biggest river in Korea, and its watershed covers about $1,325 \mathrm{~km}^{2}$ and total length is $117 \mathrm{~km}$. At the very top of the river, Hapcheon Dam is located and upper parts of river are mostly mountain areas. City of Hapcheon is located at the middle of the river and lower parts of the river are agricultural area. Water samples were taken from up and downstream of the river.

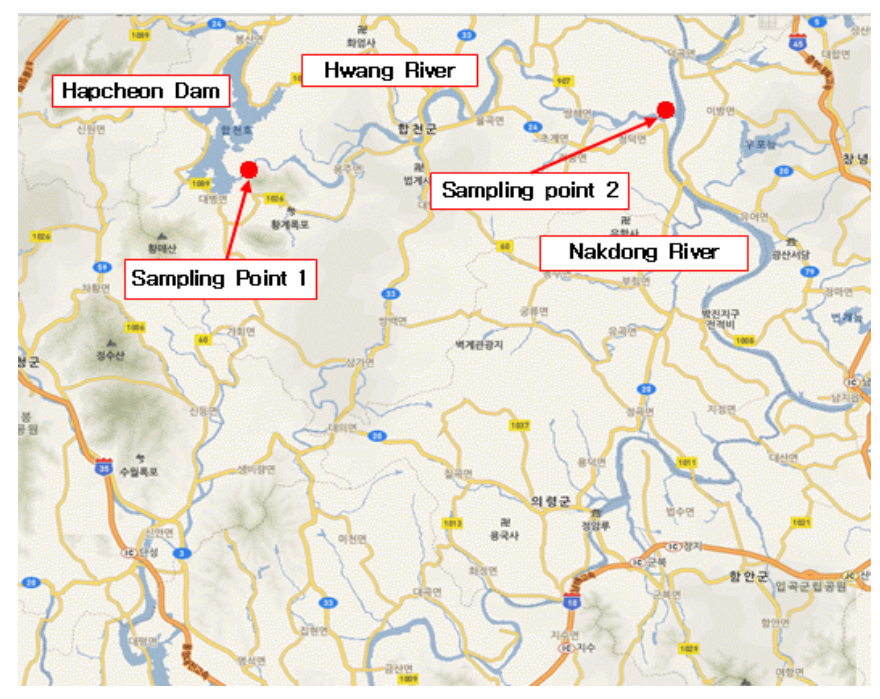

Figure 1. Study area and locations of each sampling point

The sampling point at upstream is closed to Hapcheon Dam floodgate and the one at downstream is right before the confluence of Hwang River and Nakdong River. 
Figure 2 shows the Hapcheon Dam and Sampling points at up and downstream. The height of Hapcheon Dam is $96 \mathrm{~m}$, width $472 \mathrm{~m}$ and maximum capacity 790 million $\mathrm{m}^{3}$ of water. The amount of dam discharge would depend on total precipitation and it greatly affects on upstream flow rate of Hwang River.
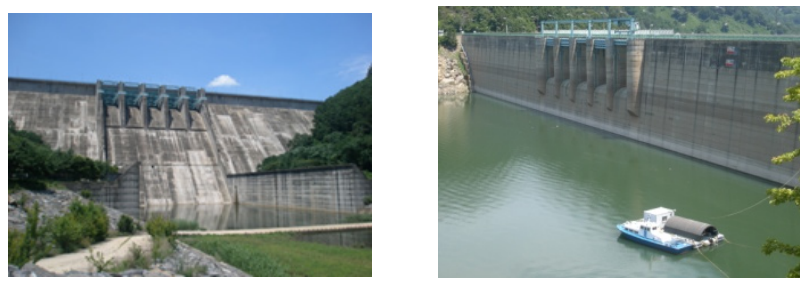

(a) Hapcheon Dam

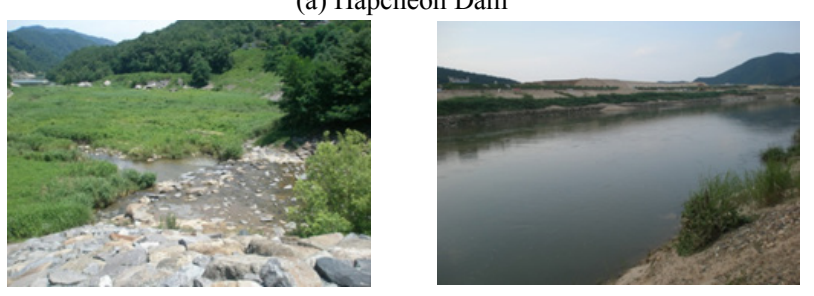

(b) Sampling point at upstream and downstream

Figure 2. View of Hapcheon Dam and sampling points

\subsection{Precipitation, Streamflow and Water Samples}

Precipitation data were provided by Korea Meteorology Administration. Hapcheon Dam discharge rates were used as streamflow data for upstream sampling station and data from automatic monitoring system of Nakdong Flood Control Center were used as flow rate for downstream sampling point. Water samples were collected on Sep. 10th 2011, Jul. 14th 2012 and Aug. 13 ${ }^{\text {th }} 2012$ and analyzed for COD, TSS, T-N and T-P. Korean Standard Methods were adopted for water sample analysis [7]. Five water samples were taken for each rainfall events. Sample 1 took before rainfall events, Sample 2 early rainfall events, Sample 3 peak of rainfall events, Sample 4 end of rainfall events, and Sample 5 after rainfall events.

\section{Result}

\subsection{Precipitation and Streamflow}

Figure 3 shows changes of precipitation and streamflow for each sampling day. Total amount of precipitations were $11 \mathrm{~mm}$ at upstream and $10 \mathrm{~mm}$ at downstream on Sep. $10^{\text {th }} 2011 ; 51 \mathrm{~mm}$ at up and $33 \mathrm{~mm}$ at down on Jul. $14^{\text {th }} 2012 ; 32 \mathrm{~mm}$ at up and $31 \mathrm{~mm}$ at down on Aug. $13^{\text {th }}$ 2012. Changes of streamflow at upstream were not followed that of precipitation since Hapcheon Dam Management Office controlled discharges. On the other hand, Streamflow at downstream responded to rainfall events. Streamflow at downstream on Sep. $10^{\text {th }} 2011$ were gradually increased with rainfall events. Streamflow at downstream on Jul. $14^{\text {th }} 2012$ were gradually decreased because streamflow were already increased with Jul. $13^{\text {th }}$ 2012 rainfall events $(43 \mathrm{~mm})$ and rainfall event before 6 p.m. on Jul. $14^{\text {th }} 2012$ was only $2 \mathrm{~mm}$ which was not good enough to re-increase flow rate. Streamflow on Aug. $13^{\text {th }}$ 2012 were rapidly increased responded to rainfall event, but it took about $14 \mathrm{hrs}$. Overall, streamflow at upstream were dependent on dam discharges and those at downstream had lagged time to respond to rainfall events.
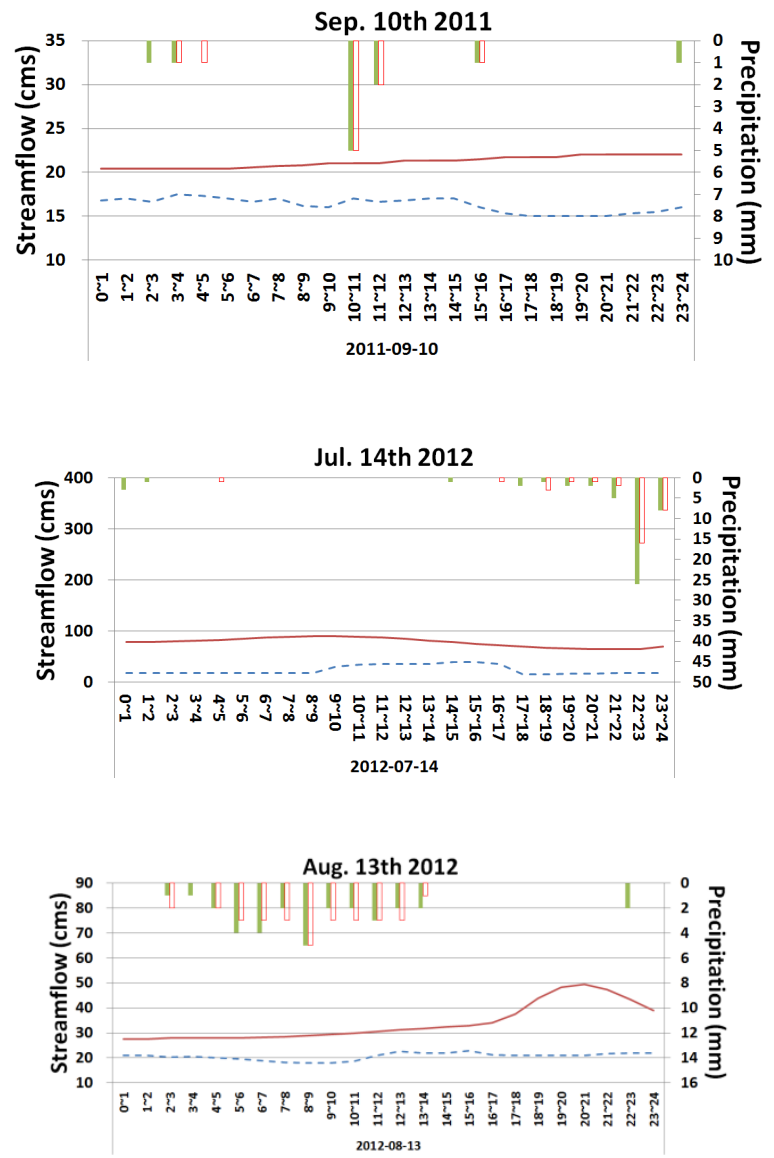

$$
\begin{aligned}
& \text { Precipitation_upper } \\
& \text { - - Streamflow_upper }
\end{aligned}
$$$$
\begin{aligned}
& \square \text { Precipitation_down } \\
& - \text { Streamflow_down }
\end{aligned}
$$

Figure 3. Precipitation and streamflow for each sampling day

\subsection{Concentration Changes with Rainfall Events on Sep. $10^{\text {th }} 2011$}

Figure 4 shows concentration for each water quality factor at up and downstream with Sep. $10^{\text {th }} 2011$ rainfall event. Overall, concentration changes for each factor were not significant except that of TSS. TSS concentrations were followed to patterns of rainfall event. In other words, TSS concentrations were increased as the rainfall event rose and then they were decreased as the rainfall event declined. Changes of TSS concentrations were, somewhat, expected since particles could be washed out from the surface with rainfall runoff and sediments on the river 
bottom might be re-suspended by rainfall events. However, concentration changes of other factors stayed in similar levels during rainfall events were unexpected. Possible reason for the result was total amount of precipitation and its pattern. Total precipitation at upstream $(11 \mathrm{~mm})$ and downstream $(10 \mathrm{~mm})$ on Sep. $10^{\text {th }} 2011$ was not enough to wash-out and bring pollutants from surface to waterbody. In addition, the study area experienced several heavy rainfall events during July and August of 2011, so most of pollutants at the watershed might be already washed out with those heavy rainfalls. Another result was concentrations at upstream were higher than those at downstream for all water quality factors. Flow rates at upstream were affected by discharges of Hapcheon Dam, so concentrations at upstream might stay in higher levels than those at downstream although the amount of precipitation was only $11 \mathrm{~mm}$. Pollutants, however, could be settled down while they flowed to downstream since river length is $111 \mathrm{~km}$ and the small amount of precipitation could not force pollutants to flow throughout such a long way. T-P concentrations stayed in low levels since most of the watershed are either mountainous area or farmland, so inflow of sewages which is main sources of phosphorous are limited.
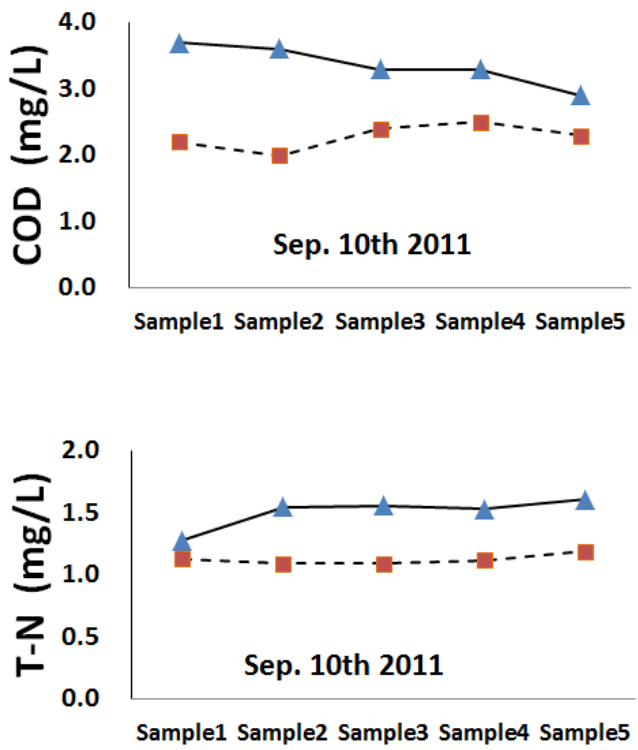
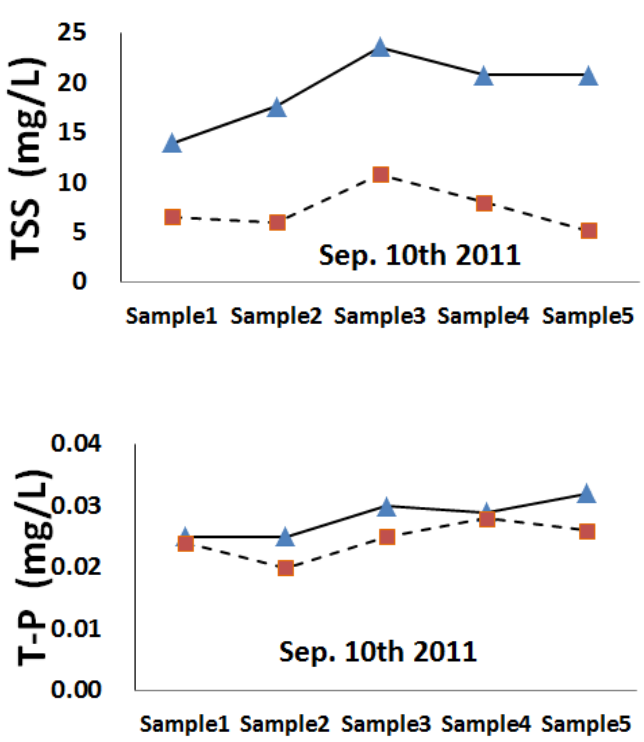

- - Downstream

Figure 4. Concentration changes for each water quality factor (Sep. 10th 2011)
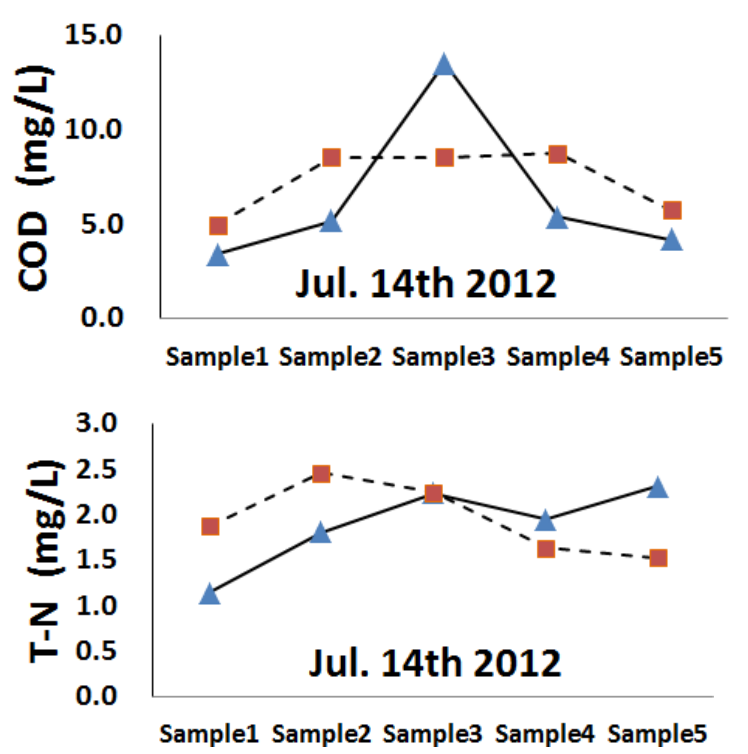
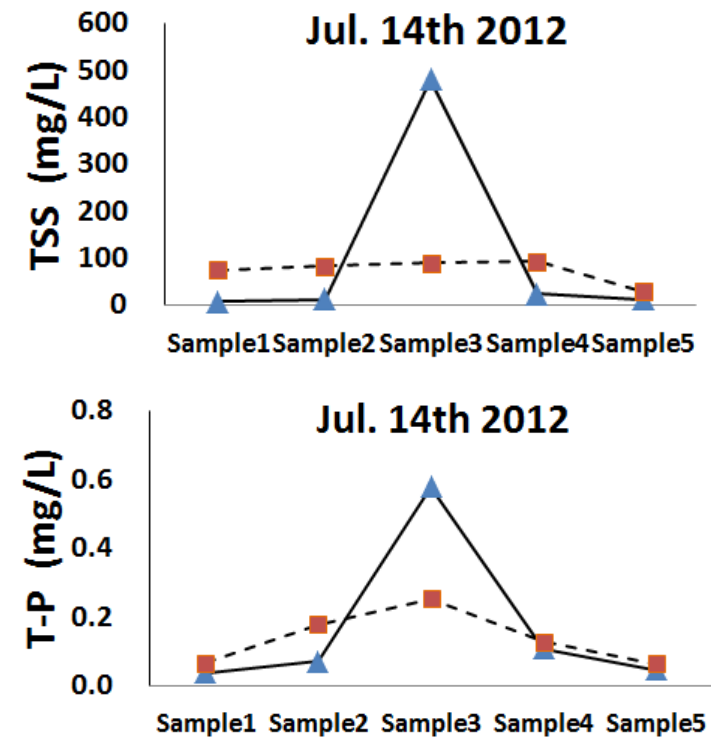

- - Downstream

Figure 5. Concentration changes for each water quality factor (Jul. 14th 2012) 


\subsection{Concentration Changes with Rainfall Events on Jul. $14^{\text {th }} 2012$}

Figure 5 shows changes of concentration for each water quality factor at up and downstream with Jul. $14^{\text {th }} 2012$ rainfall event. Concentration changes at downstream were not substantial, but their concentrations were higher than those for samples at downstream on Sep. $10^{\text {th }}$ 2011. Two consecutive days of rainfall events, Jul. $13^{\text {th }}$ to Jul. $14^{\text {th }}$, resulted in $78 \mathrm{~mm}$ of precipitation which amount could bring all pollutant both upstream and adjacent area to downstream. Concentration levels for samples at upstream with Jul. 14 2012 rainfall event were also higher than those with Sep. $10^{\text {th }} 2011$ rainfall event. In addition, concentration at upstream on Jul. $14^{\text {th }} 2012$ showed a clear pattern while those on Sep. $10^{\text {th }} 2011$ rainfall event were not. Another result for concentration changes at upstream was concentrations for sample 3 which was taken during the peak time of rainfall event showed considerably high compared to other samples except T-N concentration. The result clearly shows pollutants flowing into waterbody by rainfall events. In 2012, there was no heavy rainfall event before Jul. $13^{\text {th }} 2012$ which means the two days rainfall event from Jul. $13^{\text {th }}$ to Jul. $14^{\text {th }}$ was the first heavy rainfall event in 2012, so this rainfall event might bring all pollutants from the watershed which accumulated in the watershed during dry season. High concentrations of TSS are another proof for the fact. However, concentration changes at downstream did not have such patterns. Concentrations for samples at downstream during rainfall event still showed higher than those before or after rainfall event. Also, concentrations at downstream were higher than those at upstream except sample 3, peak of rainfall, because two days heavy rain could bring all pollutants to the downstream. The result explains how heavy rainfall right after long term dry season may affect water qualities of rivers.

\subsection{Concentration Changes with Rainfall Events on Aug. $13^{\text {th }} 2012$}

Figure 6 shows changes of concentration for each water quality factor at up and downstream with Aug. $13^{\text {th }} 2012$ rainfall event. Concentrations for samples on Aug. $13^{\text {th }}$ 2012 were lower than those on Jul. $14^{\text {th }} 2012$ since large amount of pollutants on surfaces were already washed out with previous heavy rainfall from Jul. $13^{\text {th }}$ to Jul. $14^{\text {th }}$. Concentrations, however, for each sample were increased with rainfall event and decreased after rainfall stopped since total amount of rainfall was more than $30 \mathrm{~mm}$ for both up and downstream which amount might be sufficient to wash out remained pollutants. Changes of COD and $\mathrm{T}-\mathrm{N}$ concentrations at downstream were trivial compared to changes of other concentrations. T-N concentrations at downstream showed considerably higher than those at upstream while COD concentrations at downstream stayed in similar levels with those of upstream. The result is due to the watershed characteristics. Wide ranges of farmland are located in the middle of Hwang River watershed and those areas are the main sources of nitrogen. Sources for COD are limited in this area, so COD concentrations at up and downstream stayed in similar levels.
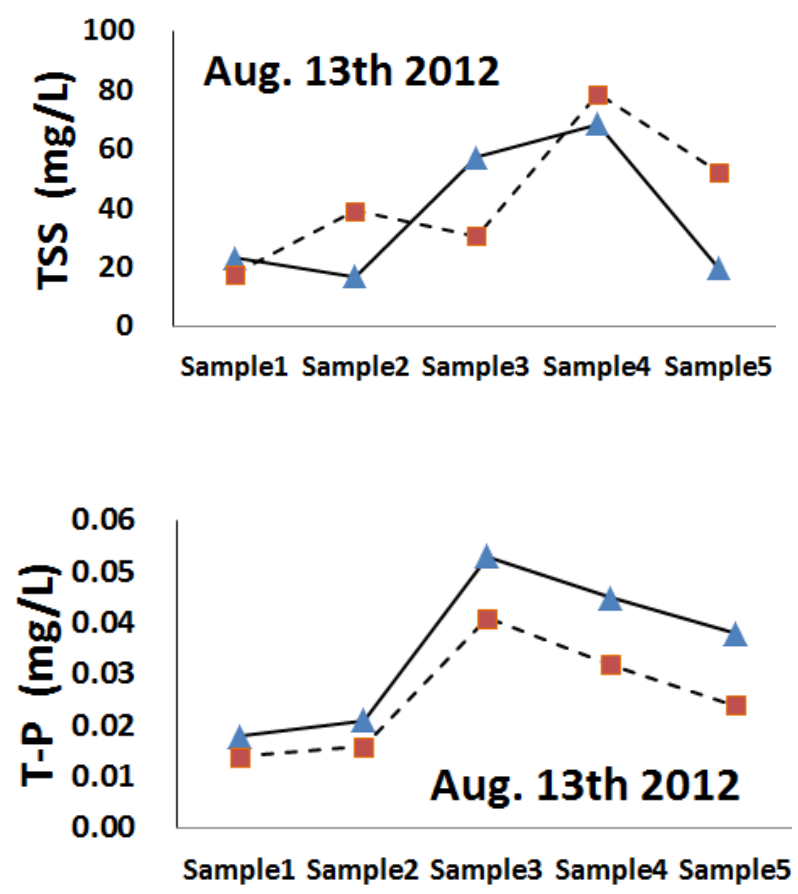

Sample1 Sample2 Sample3 Sample4 Sample5
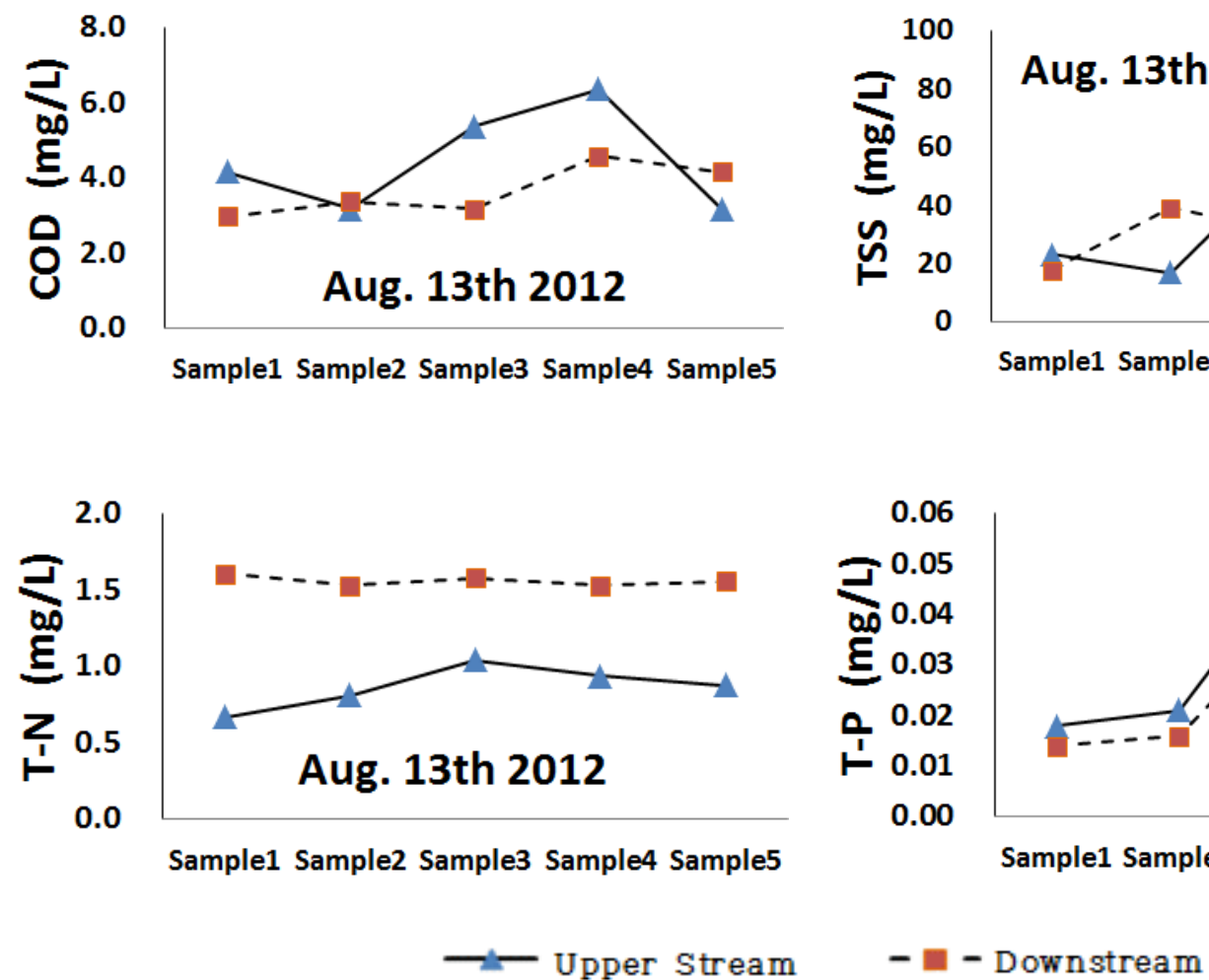

Figure 6. Concentration changes for each water quality factor (Aug. 13th 2012) 


\section{Conclusion}

In this study, effects of rainfall events on river's water quality were investigated focused on Hwang River, Korea. The amount of rainfall events and rainfall frequency is the key issue to affect on river's water quality. Certain amount of rainfall, this study $30 \mathrm{~mm}$, should occur to bring pollutants from surface to waterbody. Rainfall events after a long term dry season accelerated water quality degradations since pollutants may be accumulated on surface areas during dry season. On the other hand, degradations of river's water quality which experienced several previous heavy rainfall events were little with following rainfall events. Also, watershed characteristics should be carefully considered since water contaminations may be greatly dependent on types of adjacent areas' landcover. Overall, stromwater managements for rainfall events right after long term dry season and considering watershed characteristics should be established to have a proper management for river's water quality.

\section{REFERENCES}

[1] H. K. Bae. Modeling approaches to predict conditions of water quality using physical, chemical, and hydrological data focused on biological contaminations. Ph.D. dissertation, University of California, Irvine. 2007.

[2] C. W Kim. Watershed Characteristics Affecting Water Quality in Urban Streams, Ph.D. dissertation, University of Seoul, 2008.

[3] Y. T. Kang. Developing advanced waste water treatment systems for recovering Nakdong River, J. of Korean Soc. of Wat. Sci. and Tech., Vol.3, No.4, 21-30, 1995.

[4] J. M. Lee, C. K. Park, C. Kim. A study for source and distribution of Boron in Nakdong River, J. of Korean Soc. On Wat. Env., Vol.21, No.3, 236-241, 2005.

[5] J. E. Whitlock, D. T. Jones, V. J. Harwood. Identification of sources of fecal coliforms in an urban watershed using antibiotic resistance analysis, Wat. Res. Vol.35, No.17, 4272-4282, 2002.

[6] R. T. Noble, S. B. Weisberg, M. K. Leecaster, C. D. McGee, J. H. Dorsey, P. Vainik, V. Orozco-Borbon. Storm effects on regional beach water quality along the Southern California shoreline, J. of Wat. and Heal. Vol. 1, No. 1, 23-31, 2003.

[7] Korea Ministry of Environment. Korea Standard MethodsWater, Korea Ministry of Environment, Seoul, 2009. 